\title{
Leaders' Visions of Rehabilitation Services for Children in Ontario's Schools: Effective Collaboration between Education and Health Sectors
}

\author{
Karen E. Shannon ${ }^{1}$, Heidi Cramm ${ }^{1}$, Alison McDonnell ${ }^{2}$, Beata Batorowicz ${ }^{1}$ \\ ${ }^{1}$ Queen's University, Kingston, Canada \\ ${ }^{2}$ Limestone District School Board, Kingston, Canada \\ Email: *karen.shannon@queensu.ca
}

How to cite this paper: Shannon, K. E., Cramm, H., McDonnell, A., \& Batorowicz, B. (2021). Leaders' Visions of Rehabilitation Services for Children in Ontario's Schools: Effective Collaboration between Education and Health Sectors. Open Journal of Social Sciences, 9, 33-58.

https://doi.org/10.4236/jss.2021.911004

Received: September 30, 2021

Accepted: November 6, 2021

Published: November 9, 2021

Copyright $\odot 2021$ by author(s) and Scientific Research Publishing Inc. This work is licensed under the Creative Commons Attribution International License (CC BY 4.0).

http://creativecommons.org/licenses/by/4.0/

(c) (i) Open Access

\begin{abstract}
Leaders in Ontario's district school boards (DSBs) and children's treatment centers (CTC's) share responsibility for rehabilitation therapy services in inclusive schools. Children with or at risk of disability rely on these services to enable their participation in learning and social environments. The aim of this study was to explore how leaders in DSBs, CTCs and the community envision effective collaboration in rehabilitation therapy services to advance collaboration in service of children with or at risk of disability and their families. Seven 90-minute online semi-structured focus groups were conducted involving a total of 36 education, community and health leaders and data were analyzed thematically. An eighth focus group comprised of representatives from the seven previous groups was conducted to validate the findings and develop recommendations. Three themes were established: collaboration is a relational and intentional process, forging a path forward to serve children with rehabilitation therapy needs, and leaders' attributes needed to effect change. The participants recommended the following next steps: clarifying provincial standards for services including roles of all partners, knowledge building within schools, and utilizing existing evidence-based tools. A shared vision of rehabilitation therapy services is needed for effective collaboration between health and education sectors. Future research should involve leaders from health and education sectors, with parents, children and other partners in co-designing, implementing, and evaluating rehabilitation services in schools.
\end{abstract}

\section{Keywords}

Leaders, Collaboration, Health, Education, School-Based Rehabilitation 


\section{Introduction}

Challenges to collaboration between regulated health professionals and educators regarding rehabilitation services in Canadian schools (i.e., occupational therapy $[\mathrm{OT}]$, physical therapy [PT], and speech and language therapy [SLP]) have been well documented over the last twenty-five years (DeLoach et al., 2012; Deloitte \& Touche, 2010; Hernandez, 2013; Hillier et al., 2010; Shasby \& Schneck, 2011; Villeneuve, 2009; Wintle et al., 2017). Collaboration refers to knowledge and practice sharing between two or more co-equal parties working toward a common goal (Friend \& Cook, 2003). While several issues were noted as sources of tension in collaboration, including lack of time and poor understanding of roles, two main contributing factors were the absence of shared ownership and vision in service provision (Hillier et al., 2010; Villeneuve, 2009; Wintle et al., 2017).

Shared ownership and vision of educators and therapists working together at the classroom or school level have been documented in at least five research studies (Campbell et al., 2016; Missiuna \& Hecimovich, 2015; Missiuna et al., 2012; Phoenix et al., 2021; Villeneuve \& Shulha, 2012). In these studies, educators, therapists, and program administrators agreed upon goals and developed understanding and respect for each other's roles and expertise (Campbell et al., 2016; Missiuna \& Hecimovich, 2015; Missiuna et al., 2012; Phoenix et al., 2021; Villeneuve \& Shulha, 2012). The authors of these studies employed rigorous methodology and demonstrated positive results in advancing evidence-based occupational therapy service delivery models and inter-professional team support in schools within the complex political and regulatory framework which governs health and education services in the Canadian province of Ontario.

\subsection{Background on Ontario's School-Based Rehabilitation Services}

The school-based rehabilitation therapy services program in Ontario was instituted in 1984 as part of School Health Support Services (SHSS). This multi-ministerial initiative aimed to secure support services for children with disabilities to ensure meaningful access to education and guarantee that no child would be denied education because of disability (Deloitte \& Touche, 2010; Ontario Ministry of Education [OME], 1984). Children in school who demonstrated a risk of disability without a previous diagnosis were also eligible for service with parental consent (Deloitte \& Touche, 2010; OME, 1984). The 72 publicly funded District School Boards (DSB) across Ontario worked with a wide array of public and private providers when requesting services for children in schools.

A review of SHSS by Deloitte and Touche (2010) identified the need to "estab- 
lish alternative models of service delivery across the province to improve access and wait times" for needed disability services (p. 8). Wait times for children referred for rehabilitation therapy services between 2007 and 2009 were up to two years and the number of children on waitlists was increasing year-over-year (Deloitte \& Touche, 2010). The report also identified challenges related to increasing service demands due to the growing complexity of students' health support needs and the potential for differing interpretations of the mandate for health services in schools (Deloitte \& Touche, 2010).

In response to the report by Deloitte and Touche (2010), the Government of Ontario introduced the Special Needs Strategy (SNS) in the spring of 2014 to improve services. SNS aimed to: 1) improve early identification of special needs in children and get them help sooner; 2 ) introduce service planning coordinators for children and youth with multiple or complex needs; and 3) integrate the delivery of rehabilitation services (OT, PT and SLP) seamlessly from birth to end of school (Ontario Ministry of Children, Community and Social Services [OMCCSS], 2018). Many stakeholders, including provincial associations of therapists and the DSB Special Education Advisory Committees (SEAC), which were comprised of parents and representatives from community agencies, engaged in consultations on the SNS (Learning Disability Association Ontario [LDAO], 2020; Ontario Society of Occupational Therapists [OSOT], n.d.).

The SNS was not continued following the 2018 government leadership change (Slaughter, 2018) and management of the school-based rehabilitation service program for children in publicly funded schools was transferred from the Local Health Integrated Networks (LHINs) to the 21 Children's Treatment Centres (CTCs) in 2019 (OSOT, n.d.). Waitlists for services persisted across the province, however, with the movement of school-based rehabilitation services to CTCs, DSBs would have fewer health providers to work with to coordinate services. Now, more than 10 years have passed since the provincial review of school health support services called for leadership and a collaborative commitment from stakeholders at both local and provincial levels to improve SHSS (Deloitte \& Touche, 2010).

\subsection{Resounding Calls for Leadership Action}

For over 30 years, researchers have emphasized the importance of the support and engagement of leaders at the school and system-level to enable effective collaboration of teachers and therapists in service of children with or at risk of disability and working in partnership with parents. For many years, researchers have emphasized the importance of the support and engagement of leaders at the school and system-level to enable effective collaboration of teachers and therapists in service of children with or at risk of disability and working in partnership with parents (Barnes \& Turner, 2001; Eron, 2021; Fairbairn \& Davidson, 1993; Hernandez, 2013; Kramer-Roy et al., 2020; Nochajski, 2001; Rossetti et al., 2021; Villeneuve, 2009). A systematic review of 34 studies on collaborative mod- 
els for health and education professionals working in school settings and implications for training pointed to the need for significant work from individuals and lead agencies to ensure successful collaboration that is child-focused and inclusive of families (Hillier et al., 2010). Another scoping review consolidated recommendations for administrators' involvement in school-based health promotion, including health services in school identified 80 distinct recommendations for administrators (i.e., principals, assistant principals, superintendents), into three themes: collaboration, advocacy, and support (Webster et al., 2020). This review acknowledged the importance of further study of "administrator training, preparedness, perceptions, and beliefs related to school-based health promotion" (Webster et al., 2020: p. 14). Similarly, Rossetti et al. (2021) advocate that leaders have a responsibility to lessen the advocacy burden on parents of children with disabilities through intentional policy and practice measures that enable parent participation in decision-making for their child. Moreover, Karisa and colleagues (2020) challenge government and system leaders to re-evaluate barriers within school system design as these could limit the pursuit of inclusive education; examples of this include rigid curriculum targets and special education-oriented cohort models.

Despite the broad recognition that leaders play an important role in enabling effective collaboration between educators and therapists, there is a paucity of research on how leaders envision their role and specifically what effective collaboration looks like to them. No studies could be found where education and health system-level leaders, together, shared their insights on effective collaboration in school-based rehabilitation services (SBRS). Researchers suggested that the adoption of evidence-based service delivery models requires the inter-organizational commitment of leaders in both education and health. It also requires a systematic, coordinated approach to address the provision of training, time to meet, and monitoring and evaluation of service outcomes for and with children and families (Anaby et al., 2019; Missiuna \& Hecimovich, 2015; Phoenix et al., 2021; VanderKaay et al., 2021). A realist synthesis conducted by VanderKaay et al. (2021) identified three main mechanisms to optimize successful outcomes in the implementation of tiered rehabilitation services, which were: collaborative relationships, authentic service delivery, and reciprocal capacity building. While the important work of leaders in rehabilitation services in schools is well described by researchers, the perspective of leaders remains unstudied. A comprehensive understanding of the dynamics of effective collaboration in rehabilitation services in schools necessitates the exploration of the perspective of all partners, especially those responsible for service design, implementation and evaluation.

The purpose of this study was to explore how leaders in DSBs, CTCs and SEAC envision effective collaboration in SBRS and identify their recommendations to advance collaboration in service of children with or at risk of disability and their families in Ontario. The specific objectives of this study were to: 1) 
identify the vision of effective collaboration in SBRS held by superintendents of special education (superintendents), directors or managers of CTCs (directors) and SEAC representatives; and 2) identify what is needed to advance effective collaboration in SBRS as described by superintendents, directors, and SEAC representatives.

\section{Method}

This was an exploratory study that used a constructivist interpretative approach. The study involved focus groups with leaders of education and rehabilitation. Focus groups were used as the method of data collection to allow participants to discuss points of consensus and difference and contribute to the research process in an organic manner (Flynn et al., 2018). The study received ethical clearance in Canada in July, 2020.

\subsection{Participants}

A theoretical approach to sampling of participants was used to ensure that adequate data were generated to answer the research question (Coyne, 1997). Theoretical sampling is a purposeful qualitative sampling technique where participants are chosen based on specific characteristics (Coyne, 1997). Leaders of education and children's rehabilitation services were sought who would collectively contribute a breadth of perspectives across urban and rural regions of the province, in regional north, south-east, south-west, and central Ontario, as well as variation in the years of experience in their current leadership role (Manning, 1997). All participants were required to be fluent in English.

Participants were made up of superintendents, directors of CTCs, and SEAC members. Superintendents were required to have a minimum of one-year experience in a leadership role related to SBRS. Superintendents who had not supervised SBRS within the past 5 years were excluded. Similarly, directors of CTCs were required to have a minimum of one-year experience in a leadership role related to SBRS; the study specifically sought those who directly reported on outcomes to the Ministry of Children, Community and Social Services (MCCSS). Directors of CTCs who were not involved in operational decision-making related to SBRS were excluded and managers overseeing the program were invited to participate. SEAC members were sought who were representatives of provincial associations with a role of advocacy for children or youth with disabilities. They must have had direct experience or knowledge of SBRS. At least two participants had to be parents of children with disabilities. SEAC members who worked for DSBs or CTCs were excluded.

Within Ontario, all of the 72 DSB superintendents responsible for special education services, 21 directors of CTCs or managers responsible for decision-making in the school-based rehabilitation therapy program, and SEAC representatives responsible to advise DSB on the provision of programs and services for children were invited to participate in the study. The participants were 
recruited through email communication with assistance of Empowered Kids Ontario, the association for CTCs. A directory of emails was created to recruit superintendents and SEAC members using DSB website contact information. Individuals who responded with interest in the study were contacted by phone to review eligibility criteria and conduct verbal consent procedures.

This study included 36 participants: 15 superintendents from DSBs, seven SEAC members, 12 directors and two managers from CTCs. Five SEAC representatives, two CTC directors and one CTC manager were also parents of children with disabilities. Details about the participants can be found in Table 1. Of the 36 participants, three superintendents, three directors of CTCs and one SEAC member expressed interest in participating in the second focus group (Phase 2, as described below).

\subsection{Data Collection}

The study involved two phases of data collection. Phase 1 focused on participants' past experiences and future aspirations of effective collaboration. The goals of Phase 2 were to validate the findings from Phase 1 as a form of member-checking and to provide an opportunity for participants from each leaders' group to discuss the findings together and identify next steps in advancing effective collaboration (Lincoln \& Guba, 1985).

\subsection{Focus Group Guides}

\section{1) Phase 1}

Focus group guides (i.e., for each group of leaders) were developed using the Appreciative Inquiry (AI) framework, which included Discovery, Dream, Design, Destiny phases of exploration with participants (Cooperrider \& Whitney, 2005). This approach was chosen because the values which underlie AI-positive,

Table 1. Participant characteristics.

\begin{tabular}{cccc}
\hline Variable & Superintendents & $\begin{array}{c}\text { SEAC } \\
\text { Representatives }\end{array}$ & $\begin{array}{c}\text { Directors/ } \\
\text { Managers }\end{array}$ \\
\hline Regions & & & \\
\hline North & 3 & - & 4 \\
Central & 4 & 2 & 2 \\
Southeast & 4 & 5 & 5 \\
Southwest & 4 & - & 3 \\
\hline Years in current role & & & 2 \\
\hline$<3$ years & 8 & N/A & 9 \\
4 - 6 years & 5 & N/A & \\
$>8$ years & 2 & N/A & 14 \\
Sex & & & - \\
\hline Female & 13 & 6 & \\
Male & 2 & 1 & \\
\hline
\end{tabular}


practice-oriented, proactive, and collaborative-align with the intention of this study to bring together the views of different groups of leaders to answer the research question (Knibbs et al., 2010). Each phase of the AI framework contained a series of open-ended questions. Participants' previous experiences engaging in effective collaboration with partner organizations were explored. They were asked to describe their ideal future vision of effective collaboration in school-based rehabilitation therapy services, including what effective collaboration looks like for educators, therapists, children, and parents. The guide with questions is shown in Table 2.

\section{2) Phase 2}

A semi-structured focus group guide was developed to prompt participants to discuss their interpretation of findings from Phase 1. This inquiry specifically wanted to understand how the leader groups describe their vision of effective collaboration in SBRS and their recommendations for the next steps. The questions can be found in Table 3 .

Table 2. Phase 1 focus group guide questions.

\begin{tabular}{|c|c|}
\hline Phase & Questions \\
\hline Warm Up & - What is your role and how long have you been in your current role? \\
\hline \multirow{3}{*}{ Discovery } & $\begin{array}{l}\text { - Can you tell me about a time when collaboration between CTCs, } \\
\text { DSBs or other service provider partners was highly effective? }\end{array}$ \\
\hline & $\begin{array}{l}\text { What were the outcomes of this effective collaboration for you, } \\
\text { children, staff and families? }\end{array}$ \\
\hline & - How did the experience of effective collaboration make you feel? \\
\hline \multirow{2}{*}{ Dream } & $\begin{array}{l}\text { - What are your greatest aspirations for system collaboration between children's treatment centres and } \\
\text { district school boards in service of students and families who participate in } \\
\text { school-based rehabilitation therapy? }\end{array}$ \\
\hline & $\begin{array}{l}\text { - Free yourself from what IS and embrace the art of the possible to imagine what could be-picture } \\
\text { the ideal future vision of this collaboration. Describe what you would see, hear and feel if you } \\
\text { were observing from above. }\end{array}$ \\
\hline \multirow{6}{*}{ Design } & $\begin{array}{l}\text { - What are directors/managers, superintendents doing to facilitate this highly effective collaboration? } \\
\text { - What are therapists and educators doing to facilitate highly effective collaboration? }\end{array}$ \\
\hline & - What are children doing-how are they benefiting? \\
\hline & - What are families doing-how are they engaged as partners? \\
\hline & - What are community leaders/organizations doing-how are they engaged? \\
\hline & - What factors are at play in the scenarios you envisioned which enabled effective collaboration? \\
\hline & - What beliefs, values and attitudes are important to ensure the success of these aspirations? \\
\hline \multirow{2}{*}{ Destiny } & $\begin{array}{l}\text { - What do children's treatment centres and district school boards need to get there? } \\
\text { What are the top three things/resources/supports? }\end{array}$ \\
\hline & - Please finish this sentence: Wouldn't it be great if... \\
\hline
\end{tabular}


Table 3. Phase 2 focus group guide questions.

\begin{tabular}{|c|c|}
\hline Phase & Questions \\
\hline Icebreaker & $\begin{array}{l}\text { Please share your current role in relation to school-based } \\
\text { rehabilitation therapy services and then tell us what would } \\
\text { your super power be and why? }\end{array}$ \\
\hline $\begin{array}{l}\text { Participants will } \\
\text { collectively } \\
\text { answer the } \\
\text { questions: }\end{array}$ & $\begin{array}{l}\text { - Based on Phase } 1 \text { findings, what is the vision of effective } \\
\text { collaboration in school-based rehabilitation therapy } \\
\text { services for these Ontario leaders: } \\
\text { - Superintendents of education? } \\
\text { - Directors of Children's Treatment Centres? } \\
\text { - Special Education Advisory Committee members? } \\
\text { - What is common to all focus groups? } \\
\text { - What is unique to each category of focus groups? } \\
\text { - What questions remain? } \\
\text {-What next steps are needed to create a shared vision for } \\
\text { therapy services? }\end{array}$ \\
\hline
\end{tabular}

\subsection{Procedure}

In Phase 1, seven 90-minute online focus groups using Microsoft Teams took place between August 11 and October 15, 2020. Out of seven focus groups, three groups involved superintendents (four, seven, and four participants), three groups included directors and managers (five, five, and four participants) and one focus group was conducted with SEAC members (seven participants). All sessions were audio-and video-recorded through Microsoft Teams. In Phase 2, a 90-minute focus group comprised of six representatives of the previous focus groups (the representative from the seventh group was not able to attend). The first author facilitated all the focus groups and a research assistant documented observations of participant engagement within the focus groups. The recorded data from all focus groups were transcribed verbatim and de-identified.

\subsection{Data Analysis}

Data from Phase 1 focus groups were analyzed using the inductive thematic approach, following Braun and Clarke's (2012) six-phase process (Willig \& Rogers, 2017). The six phases included familiarization with the data, generating codes, theme development, reviewing and defining themes, defining and naming themes, and producing the final report (Willig \& Rogers, 2017). This approach enabled pattern development in each of the three sets of data, within the unique social construction of respective participants, that is, publicly funded education, health care, and advisory committees to DSBs. A research assistant and the last author completed independent coding of data; all data and $25 \%$ of Phase 1 data respectively. Four iterations of themes and subthemes were refined 
by the four authors over a period of three months, arranging and rearranging the data to best resolve the research question. Codes were assigned to excerpts from each transcript. Then, like leader groups were reviewed together. Finally, codes were reviewed across excerpts from all leader groups. Themes and sub-themes derived in the thematic analysis process were then reviewed across all the data sets collectively. Ultimately, three themes were developed. The first two themes each contained five subthemes and the final theme contained three subthemes. All of the themes and subthemes were validated with full consensus by Phase 2 focus group participants.

\subsection{Trustworthiness}

Reflexivity and transparency were important practices in conducting this study as the first author and principal investigator was a superintendent of special education at the time of data collection and analysis. The first author kept a reflexive journal throughout the study and shared a formal reflexivity statement, outlining thoughts, assumptions, and presumptions on the topic of effective collaboration in SBRS with the research team. The "insider researcher' phenomena and the recognition of assumptions were identified for all prospective participants in the Letter of Information and during the informed consent process (Creswell \& Creswell, 2017). Other members of the research team included two OTs (Ph.D.) with practice and research experience in school-based services and a superintendent of special education from Ontario. The full research team was included in all phases of the thematic analysis process as a form of peer debriefing. Authenticity was supported through the researcher/participants relationship as co-learners constructing meaning together in Phase 2 (Manning, 1997).

\section{Findings}

The thematic analysis resulted in the following three themes: 1) collaboration is a relational and intentional process; 2 ) forging a path forward to serve children with rehabilitation therapy needs; and 3) leaders demonstrate attributes needed to affect change. The first theme concerns how leaders have engaged in collaborative work and what anchors the processes of successfully partnering in service of children and families. The second theme concerns what may be achieved or aspired to in SBRS. The final theme concerns the qualities, skills, and beliefs leaders identify as important to support effective collaboration. This final theme transcends and links the first two themes as the qualities, skills, and beliefs of leaders identified were referenced in relation to previous effective collaborations and influence how participants see the path forward in SBRS. Together, the three themes tell the story of how leaders of CTCs and DSBs as well as SEAC representatives envision effective collaboration, what their aspirations are for the future of services, and what attributes leaders may leverage to accomplish the work ahead. Table 4 depicts the themes and subthemes. 
Table 4. Thematic analysis themes and subthemes.

\section{Theme 1: Collaboration is a relational and intentional process}

Subthemes:

- Working together as equals

- Aligning a vision as partners

- Learning stance needed by all

- Child and family focused/included at the table

- Closing communication gaps

Theme 2: Forging a path forward to serve children with rehabilitation therapy needs

Subthemes:

- Address systemic barriers to services for segments of populations

- Timely services for all students

- Tiered approach to services

- Schools as community hubs for services

- Provincial guidelines/standards for services

Theme 3: Leaders demonstrate attributes needed to effect change

Subthemes:

- Qualities

- Beliefs

- Skills

\subsection{Theme 1: Collaboration Is a Relational and Intentional Process}

The first theme concerns how leaders have engaged in collaborative work. Leaders described past and current collaborative initiatives that resulted in positive outcomes for children and their families as well as the service providers themselves. The key common factors to these successful collaborations are summarized in the five subthemes; 1) working together as equals; 2) learning stance needed by all; 3) child and family focused/included at the table; 4) closing communication gaps; and 5) aligning a vision as partners. Participants describe these five factors as foundational to intentionally building relationships supportive of effective collaboration.

\subsubsection{Working Together as Equals}

Participants described relationship building between health and education workers, including leaders, as essential to effective collaboration as exemplified by PCTC7: "When clinicians had that ability to work more closely alongside rather than popping in and out... that's what helps to move forward this-this openness and understanding of one another's strengths and gifts". The leaders shared the importance of understanding each other, mutual respect and working in partnership when describing their own experiences of effective collaboration:

Successful collaboration, for me, really helps to make everyone feel valued and what they bring to the table is valued. We all have a contribution to 
make-that-acknowledgement that we really can't do all of this alone, we need to work together. (PCTC10)

Participants also discussed their perceptions of factors like funding, which can erode a partners' sense of equality.

I do find they get funding to do things each and every time and we don't. We get new challenges and so, just the funding inequity can be a bit-you know... you just have to put down your pencil and go home. (PCTC2)

\subsubsection{Learning Stance Needed by All}

The importance of a leader's commitment to learning was discussed in all focus groups. The engagement of leaders modelling learning within the context of collaborating with partner organizations was referenced as the work of leaders:

In order to serve the children in our care, we need to work collaboratively and we all bring different [inaudible] to the table. I haven't been part of a group where I haven't been enriched by the conversation because we have different disciplines and different perspectives and different expertise at the table... you're also there to learn... that learning stance on everyone's part. (PSO9)

Participants reflected on the continuous nature of the learning journey when advancing initiatives across multiple organizations:

Keep a focus on the value of collaboration and shared outcomes, it's the work of a generation... we need the art and the science, um, and the partnerships and the relationships to get this right and that it will be a learning journey, it is a learning journey. (PCTC9)

The contributions parents make to the learning of the team as well as the support they may need was also identified by participants: "[W]hen I started this process, I certainly didn't know what OT was, or... physiotherapy can help with 'this' problem" (PSEAC3).

\subsubsection{Child and Family Focused/Included at the Table}

A range of effective collaborative initiatives described by leaders, including transition to school partnerships, operated from a clear protocol where roles were outlined. This included what parents could expect: "[T]he core element is that it was jointly developed... co-defined and more recently, co-defined with family" (PCTC5). The participants identified sharing common understandings about how parents and children should be engaged in services and decision-making as critical to effective collaboration: "[P]roviding an opportunity for voice for each of those contributors, including the child...bringing the child's voice into the conversation as an active partner where possible" (PSO9). Participants acknowledged that parents have not always felt that they were equal contributors in decision-making and planning of services for their child: 
Put parents first-they're the ones who are advocating for the child. The mentality that they have to be invited to be part of the team, even though it's their child... that whole mentality needs to change. (PSEAC5)

\subsubsection{Closing Communication Gaps}

SEAC representatives and superintendents emphasized the importance of ongoing problem-solving related to efficient ways to share information. A SEAC representative who is also a parent commented: "I think that coordinated communication is probably one of the biggest needs from my point of view... multiple service providers, multiple people who then need to get that information" (PSEAC6). Beyond improving the logistical flow of information, improving communication strategies demonstrates concern for fostering these intentional relationships and possibly increases partners' access to each other, "[I]f there were shared kind of data integration system that would allow for easy access of... information amongst the agencies... at least something that makes sharing information simpler..." (PSO9).

\subsubsection{Aligning a Vision as Partners}

Aligning a shared vision for SBRS was recognized as a priority by superintendents, SEAC representatives, and directors of CTCs to anchor effective collaboration. Participants discussed the importance of working toward agreed upon goals within the context of a shared vision:

If we all mainly speak the same language... have the same outcome goal in mind... sometimes educators believe they're talking about learning and they're talking about curriculum. And sometimes therapists are talking about something sort of different... so, I mean, at the beginning of it is trying to be able to define what's-what's the outcome that we're all trying to be able to achieve in this process? (PSO3)

Superintendents and directors of CTCs recognized the range of interpretations of the mandate and purpose of SBRS program currently causing confusion and frustration for DSBs, CTCs, and parents.

Reconciling the ambiguity of whether the purpose of the program was for services for school-aged children in public school environments or services for children to enable their participation in meaningful education programming was an important priority discussed by participants:

I don't think we have a common understanding of what the purpose of school-based rehab services is. The fundamental philosophy or purpose of school-based rehab services versus rehab being provided to school-aged children while they're at school is something I'd really like to explore. (PSO8)

Leaders in CTCs characterized the challenge of interpretation in a similar way: School-based rehab has a mandate about school and participation in school... it is the funded service for rehab for school-age children. It doesn't take into ac- 
count rehab needs that really aren't about going to school. So we really need to look at, what is the mandate of this school-based rehab service that we are providing? Need a home, school, community mandate with open referral. (PCTC10)

Ensuring that services meet the individual needs of the child was emphasized by parent representatives within the SEAC focus group: "It needs to be more needs-centered. It seems to be just, 'well, this is what you get' and it's generally inadequate in terms of the amount of time spent on it" (PSEAC3). The need for improved collaboration on goal setting was also noted: “... it would be better for everyone to be on the same page in terms of setting goals. There is often a disconnect between medicine and education" (PSEAC7). Focus group participants expressed an interest in participating in a process which would facilitate the creation of a common vision for services: “[W]ouldn't it be great if we could re-envision and design from the ground up what the goal and purpose of school-based rehab services is, together" (PSO8).

\subsection{Theme 2: Forging a Path Forward to Serve Children with Rehabilitation Therapy}

\subsubsection{Needs}

This second theme concerns what may be achieved or aspired to in the future for SBRS. In discussing their aspirations for a better future for SBRS, participants identified key areas which would require the commitment and action of partners. These five subthemes capture what must be done to address current challenges and create a more equitable and accountable program: 1) address systemic barriers to services for segments of populations; 2) timely services for all students; 3) tiered approach to services; 4) schools as community hubs of service; and 5) provincial guidelines and standards for services.

\subsubsection{Address Systemic Barriers to Services for Segments of Populations}

All participants emphasized the importance of equitable and consistent service to children and families as a core priority. Disparity in the range of services available to children in rural settings compared to urban environments as well as for children in northern Ontario was noted by superintendent, director, and SEAC participants. A significant gap in services for Indigenous children and families who attend any of the six First Nations schools in Ontario was identified as a concern by participants in three focus groups. CTC leaders discussed the challenge as a provider: "There's a disconnect when you're a service provider to mainstream school boards but also federally funded Indigenous schools on reserve" (PCTC6). A SEAC representative spoke to the inequity of services for Indigenous children and families in First Nations schools: “... if they attend school on reserve, they are no longer able to receive any treatment... I just want to let you know that all First Nations schools are in this position if they're on reserve" (PSEAC2). Securing services in French was identified as an issue for the 12 French language school boards and the CTCs who are supporting Francophone 
children and their families: "[W]ith the consistency, the schools that are further up north aren't getting the same type of services that the schools are closer to the school board. We don't always have the French services within the agencies but it's still part of the mandate" (PSO7).

\subsubsection{Timely Services for All Students}

Improving timely access to services for children and families across the province was a concern shared by participants and refers to the elimination or reduction of waitlists: "I think one of the challenges would be, you know-our waitlists... we have long waitlists for kids and, you know, schools are desperate for our services" (РCTC8).

Participants discussed factors which may impact the current waitlist situation including the quality of the referral process, under-staffing of therapists, and inefficient service models. The consequences of lengthy waitlists for children and families were a shared concern for participants:

[K]ids were being put on a 2 to 3 year wait list... we need to re-evaluate how we're delivering this service 'cause when it's not working, the child is the one that suffers over this whole process. (PSO3)

Improvements in the timeliness of services was recognized as important to circumvent further inequities in access to services based on a parent's ability to advocate effectively or pay for services: "I've heard from a few parents where they've been waiting for services to come through the school, services haven't come, so they paid privately" (PSEAC5).

\subsubsection{Tiered Approach to Services}

While service models vary across the province, superintendent and director participants collectively supported the benefits of tiered service models to provide universal, targeted, and intensive supports for children in the school environment. Superintendent and director participants discussed preference for tiered models and also articulated their perceptions of the implications for their respective organizations, children, and families: "I would really envision in schools is that strength of teamwork, that if we were looking at a tiered model that we've got buy in from everybody, at a top level as well as all through the system" (PCTC8). Potential long-term benefits were identified:

I would love a model that was more focused on tier one and tier two...that whole proactive piece... if we had the ability to do more tier one and tier two... possibly there be less tier three and then less, you know, people on a wait list. (PSO16)

SEAC participants who were parents, expressed dissatisfaction with their experiences with consultative models of service, from both client and clinician perspectives: “ $[\mathrm{M}] \mathrm{y}$ son will see a speech therapist once and then won't see her again for a couple of weeks or a couple of months. By that time they've lost the 
connection... it shouldn't be so consultative" (PSEAC3). An SEAC representative who was also an OT commented: “[F]rom a clinician point of view, if I'm going in to see a kiddo at school and then I'm not approved for another visit for another eight months, how am I doing my due diligence as a clinician?" (PSEAC1).

\subsubsection{Schools as Community Hubs for Services}

The role of schools within communities as service hubs for children and families was discussed in four of seven focus groups. Participants discussed comparable concepts of schools as service hubs where health services for children would also be available during the school day within a school facility. Participants emphasized the advantages this co-location of health and education services would provide to families:

We really focused on the needs of the family to access services and get supports that they require in their own neighborhoods... resulting in the development of community hubs and many of them inside the walls of schools, with clinical rooms, with drop-in sites. (PCTC7)

One comment agreed to by all SEAC representatives concerned access to services in schools was this:

For me, a big one is just a space-to make sure that there is space available to meet in schools and to make sure that care is available in schools. It's really not just convenient but almost imperative, I think that some of those services are consistently available in schools. (PSEAC6)

Planning for services around the life of the child in their environment was a common element of the conceptualization of schools as community hubs:

We need to see our schools as community hubs and not the center of education only. So, if our schools are student-centered places for service and learning and community connections, it's not our building that we're welcoming our treatment partners into. It's where the students are located that we co-serve. Sometimes, we're like, "but in our house this is what's needed or not needed" and we really need to enter those conversations differently. We own some responsibilities, but owning the property doesn't mean power within the service model. (PSO15)

\subsubsection{Provincial Guidelines/Standards for Services}

The absence of provincial guidelines and standards for service were identified by all leaders as a challenge to achieving consistency and a shared vision for SBRS. SEAC leaders emphasized the importance of provincial guidelines for transparency and accountability. Participants shared varying opinions on what actions should be taken by the Ministry of Education (MOE) and MCCSS within the provincial government:

More higher alignment at the ministry level between, um, MCSS and Min- 
istry of Education in terms of some of those higher overarching policies... we do a lot of great work but unless we address policy alignment we're still gonna, I think, have those barriers in place. (PCTC6)

Leaders and SEAC representatives identified a need for clarity in vision:

There's no provincial vision on this, they're-we have all inherited a system that... and I'm not pointing fingers. It would be very hard to find someone who thought school health support services was working well... there's no provincial sort of oversight into what the program should look like, what kids should expect, or family... (PCTC12)

Concern for improved accountability was also shared:

I think there should be... have mandated times for, you know, a time a referral is picked up to when there's a first contact with the parent and then there's a first time seen... I think would really help with some of that accountability moving forward. (PSEAC1)

Revising current policies in education which pertain to health services in schools was prioritized by leaders: “... an update in PPM 81 [policy program memorandum 81] which was written in 1984, that would be a wonderful place to start" (PSO3). All participants saw a role for provincial leadership within the MOE and MCCSS to contribute to forging the path forward in SBRS by providing clear guidelines and standards for services which would support consistency, transparency, and accountability.

\subsection{Theme 3: Leaders Demonstrate Attributes Needed to Effect Change}

This theme concerns the qualities, skills and beliefs superintendents, directors of CTCs and SEAC representatives' value and bring to their work with partners in other organizations. The term "qualities" was selected as participants described growth and development of these attributes within the experience of working with others as opposed to static personality traits. Similarly, the term, "beliefs" was selected over "values" as participants identified beliefs as tangible and measurable. Participants explicitly identified attributes that they felt were important for leaders to collaborate effectively and build positive working relationships. References to qualities, skills, and beliefs were also embedded in the descriptions of their experiences of effective collaboration as well as their aspirations for future partnerships in SBRS.

\subsubsection{Qualities}

The qualities explicitly identified by participants were: flexibility, openness, courage, humility, honesty, trustworthiness, respect, and vulnerability. Participants spoke to qualities which support effective collaboration: "And, you know, that idea of being able to trust and being a little bit vulnerable, especially for myself coming in new, I think that is probably the most valuable piece of that for 
me" (PCTC14).

Similarly, participants provided insight into how their qualities as leaders show through the way they engage with others in collaborative work:

My view is if we all have the child at the center of our things... we have to go into it... with that idea that, I don't know everything, the whole idea of collaboration is to get everybody's ideas at the table. Who do you have around that table that's going to push our thinking? Then we have the attitude of respect and um, vulnerability. (PSO17)

\subsubsection{Skills}

Specific skills were identified by superintendent and director participants as important to their ability to work in partnership with each other. The skills common to both groups of leaders were: communication, strategic thinking, use of evidence, advocacy, relationship building, and problem-solving. Participants described the skills leaders need to advance effective collaboration in rehabilitation therapy services for children in schools: "[A]dvocacy for the resources needed to deliver the dream... quality management, data management, accountability to funders" (PCTC6). Skills were identified that support leaders in the challenging work of transforming services:

It's really about, um, leader agility and um, a culture of innovation and a little bit of risk tolerance. Because it feels as though those are the things that stifle any sort of innovative changes to the current state... that actually has to come from the top, those behaviours. (PCTC14)

Skills that are critical to developing and maintaining relationships were identified by participants: "I think there's some soft skills that we would expect that as professionals we bring to conversations arriving at a common purpose... complex problem-solving" (PSO5).

\subsubsection{Beliefs}

Three core beliefs were emphasized by superintendent and director participants as important to advancing their work as partners in SBRS. The core beliefs were: primacy of needs of child/family, belonging, and inclusion. Participants discussed their own beliefs and the importance of partners having common beliefs in achieving effective collaboration: "What happens in the effectiveness boils down to individuals and their attitudes and their beliefs, that's on both sides of the fence" (PCTC10). Leaders expressed appreciation for recognizing the positive attributes of children and habilitative approaches to growth: "There has to be a core foundation in the belief of growth, and-and resiliency of kids because that mindset shift that sometimes maintaining skill is the growth or-or slowing the loss of skill" (PSO15). Participants reflected on the impact of the absence of common beliefs when working as partners: "We're just making inroads with the principal's groups. The fact the principal has so much weight within their own schools, um, if we want to get to challenges, that has been a challenge for every- 
thing" (PCTC15). The importance of supporting principal capacity building for collaboration with partners was discussed in all seven focus groups:

I do feel like there's, there's some work that I didn't do, maybe I didn't have the knowledge as a principal so I do think there's some layers there that, knowledge building for principals that would in turn build some knowledge for staff and then I think the collaborative piece would, um, or could maybe flourish. (PSO16)

The work of leaders as champions of inclusion was discussed: "Every kid needs to belong... we all have a role to play in building the inclusiveness of our communities" (PCTC1).

\subsection{Recommendations of the Mixed Leader Group}

After reviewing all themes and subthemes, participants discussed how the findings resonated with them offering the following comments: "I think it looks good" (PCTC9). "It's not surprising" (PCTC10). "I think I like the way it's-it's themed, um, and there's nothing in there that catches me off guard, that's for sure" (PCTC8). "I would agree with our colleagues. When I look through the lens of the families, the service providers and then the boards, um, I think you can see how that would resonate with all three" (PSO15). "Yeah, no, it looks really-it's well organized, it's thoughtfully done" (PSEAC6). "So, I really do like the way it's laid out... very supportive of it" (PSO12). In addition to validating the themes and sub-themes identified within phase 1 data, participants in phase 2 agreed that the purpose and mandate of school-based rehabilitation therapy services should be clarified at the provincial level.

Participants identified three recommendations which would support advancing effective collaboration in the school-based rehabilitation program. They were: 1) seek inter-ministerial directives including provincial standards for services and guiding principles for local decision-making; 2) focus on knowledge building for school leaders and other educators, including pre-service learning for educators and clinicians, on co-serving children and their families; and 3) utilize tools and resources available and proven to be effective in Ontario.

\subsubsection{First Recommendation: Seek Inter-Ministerial Directives}

The first recommendation participants discussed was the need for inter-ministerial directives with provincial standards articulating what CTCs and DSBs should offer as well as guiding principles to support local decision-making. Clarity and consistency regarding what services should be offered by DSBs and what should be offered by CTCs were discussed by participants: "We [CTCs] wouldn't all align provincially-you know-the service models, etc. We really need standards, we need guidelines what really impacts this is the differences in what is occurring in school boards with their internal services" (PCTC10).

Clear leadership direction at the provincial level was emphasized: It's difficult to collaborate in a complicated system, like this one, without having 
clear, uh-clear leadership on a really-a really large level. What we end up doing is to recreate solutions to a very similar problem in a lot of different boards. (PSEAC6)

Recognizing that many decisions will need to be made locally, participants discussed the benefits of having common guiding principles to anchor their collaborative work:

Those high-level parameters, um, that will guide leaders at the local level to make the decisions that need to be made would be incredibly helpful... there needs to be an interprofessional approach and family-responsive to families. It needs to take the whole child into consideration within a child development framework. (PCTC9)

\subsubsection{Second Recommendation: Advocate for Knowledge Building}

The second recommendation involved advocating for a focus on knowledge building for school leaders and other educators and pre-service learning for educators and clinicians on co-serving children and their families:

Imagine if SBRS was a module within Faculty of Education programs where we look at whole child development, um, and truly serve through a student and family lens... when pre-service education programs, um, and clinical training programs vice-versa, speak to educational partnerships on serving the whole child. (PSO15)

Preparing and supporting school leaders for collaboration with health partners and parents of children with disabilities were identified needs to be addressed:

Many of us come through as educators in different areas of specialty and then have to learn about this-this whole other world... we're good at understanding curriculum and delivering good pedagogy, but this is not our area of expertise... very few of us have this professional lens... we could really use some support. (PSO12)

\subsubsection{Third Recommendation: Use Effective Collaboration Tools}

The third recommendation was to utilize tools available and proven to be effective in advancing collaboration in SBRS and family-centered goal setting. Specifically, participants discussed the benefits of adopting evidence-based tools for functional goal setting (Rosenbaum \& Gorter, 2011) and Partnering 4 Change (P4C), an integrated rehabilitation services model, piloted in Ontario schools:

Top of mine would be the CanChild work on-on the success and making things very functional and-and really, it's about-it really is about, um quality of life for kids and friendships and function and all of those things. (PCTC8)

Participants discussed the "silver linings" of the pandemic, specifically how 
using technology to deliver health and education services was beneficial for some children and families. Continuing to look for ways to use technology to solve problems, increase access to service virtually, and improve communication were recognized as important opportunities going forward: "I feel like technology has a lot of efficacy in these areas if it can be properly leveraged, whether it's, uh, sharing records, or whether it's meeting with students, helping to bring together students who are, uh, all over the place" (PSEAC6).

\section{Discussion}

Participants in this study identified the need to clarify the purpose and mandate of the SBRS program as a key condition to enabling effective collaboration between DSBs, CTCs, and families as a common vision for services currently does not exist. Resolving the ambiguity between "school-based" services and services for "school-aged" children in schools was identified as an important philosophical and operational priority. The current name of the program (i.e., school-based rehabilitation) seems to perpetuate the ambiguity as it ties the program to a historic policy structure intended to secure access to education for children with disabilities in inclusive school environments. It qualifies services to the physical and conceptual constructs associated with school life, as opposed to the life of the child, and fails to represent the inclusion of habilitative approaches to therapy. The Deloitte Report of 2010 noted a concern regarding the emergence of different interpretations of the purpose and mandate of various School Health Support Services (SHSS) including SBRS (Deloitte \& Touche, 2010). The authors of the report cautioned that "without a program mandate that is clearly understood by stakeholders, it is difficult to fully define accountability, roles and responsibilities for the SHSS program" (Deloitte \& Touche, 2010: p. 36). Similarly, to Deloitte and Touche (2010), the findings of the current study point to challenges and confusion related to goal setting for children as well as expectations of school leaders regarding their engagement in supporting SBRS in schools, all of which speaks to the need to define roles and responsibilities related to a clearly understood mandate.

The group learning method utilized by Villeneuve and Shulha (2012) leveraged shared learning among participants for the purpose of guiding future practice. Similarly, PAR methods were used in studies conducted in Ontario since 2008 to leverage the principles of collaboration and partnership within communities to foster ownership and sustainability of system transformation in therapy services for children in schools (Campbell et al., 2016; Missiuna \& Hecimovich, 2015; Phoenix et al., 2021). This study showed that engaging superintendents of DSBs, directors of CTCs, and SEAC representatives together with parents, children and youth in PAR studies to create guiding principles for local decision-making in SBRS is an important future direction for research as it has the potential to foster shared ownership and accountability.

Leaders in this study emphasized the importance of being open to learning 
beyond professional boundaries when working with families and colleagues across organizations. This finding is at the heart of growing in understanding of the roles of partners, building relationships, and developing a team approach to service provision as described in studies involving therapists and educators in Ontario (Campbell et al., 2016; Missiuna \& Hecimovich, 2015; Missiuna, Pollock, \& Levac et al., 2012; Phoenix et al., 2021; Villeneuve \& Shulha, 2012; Wintle et al., 2017). Further study of how leaders engage in learning beyond their professional boundaries is needed so that it may be cultivated through evidence-informed strategies.

Participants in phase 2 of this study provided a recommendation of pre-service learning programs for educators and therapists to train in co-serving children with or at risk of disability in school environments. The same recommendation for pre-service learning programs for educators and therapists on co-serving children and families has been promoted by researchers on educator/therapist collaboration (Anaby et al., 2019; Hernandez, 2013; Wintle et al., 2017). The need to support school leaders through knowledge building on effectively partnering with therapists and families was emphasized by superintendent participants in this study. Evidence supporting such an approach highlights the important role school leaders play in creating conditions which enable effective service partnerships in schools (Anaby et al., 2019; Campbell et al., 2016; Missiuna \& Hecimovich, 2015; Phoenix et al., 2021; Rossetti et al., 2021; Villeneuve, 2009; Villeneuve \& Shulha, 2012; Wintle et al., 2017). Learning was highly valued by participants and was emphasized as the preferred way of having everyone enter into partnership (i.e., the learning stance), as well as a priority output for all partners according to their specific needs. This study did not explore how leaders described their capacity to engage effectively with colleagues from other organizations or what professional learning they may have had to support their skill development as collaborators. Given the importance and inter-dependence of health and education outcomes, further research on how leaders in DSBs and CTCs prepare professionally for inter-organizational collaboration would be beneficial.

A final recommendation from participants in phase 2 was to utilize tools available and proven to be effective in Ontario schools to improve collaboration in school-based services and family-centered goal setting. This finding is unique as it is the first time education and health leaders responsible for these services have shared their vision of a path forward for effective collaboration which aligns with and builds upon research studies on tiered service designs. It also signals that leaders in DSBs, CTCs, and SEAC may be ready to embrace, together, an integrated service model which involves a continuum of universal, targeted, and intensive therapy services within the school environment and function-oriented, child-centered goal setting. The alignment between how participants of the current study described what is needed for effective collaboration in rehabilitation services in schools and the macro, meso, and micro-level contextual factors for effective tiered services outlined in a recent conceptual study by 
VanderKaay and colleagues (2021) is striking. This suggests that participants' vision of effective collaboration is consistent with research findings on what optimizes outcomes in tiered service models.

Several studies emphasized the necessity of inter-organizational commitment of leaders in education and health to facilitate the conditions needed for a systematic, coordinated approach to the adoption of evidence-based service delivery models and frameworks (Anaby et al., 2019; Missiuna \& Hecimovich, 2015; Phoenix et al., 2021; VanderKaay et al., 2021). This was a point of consensus among participants of the current study; however, it was beyond the scope of this study to explore the extent to which leaders held common definitions related to tiered or integrated services, for example, universal, targeted and intensive therapy. Further study is warranted on their perceptions of tiered service models and on how education and health leaders engage in the adoption of evidence-based models. The will to change structures and policies and the collaboration of leaders addressing the need for change in rehabilitation services in schools aligns with Karisa and colleagues' (2020) call for thoughtful action of school systems to advance inclusion of children with or at risk of disability.

\section{Implications for Policy and Practice}

A review of regulations and provincial policies concerning SBRS, including PPM 81 , was acknowledged by the participants in this study as a long-overdue necessity to improve the clarity, purpose, and mandate of the SHSS program. This finding mirrored recommendations documented in the Deloitte Report published 11 years ago, which indicated that a review of PPM 81 was necessary in order to resolve issues of varied interpretation of the purpose and scope of SHSS, including SBRS (Deloitte \& Touche, 2010).

The findings of this study highlight the need for leaders and parents at both the provincial and organizational level to work toward a shared vision of effective collaboration. In addition to reviewing regulations and policies governing the provision of services, participants recommended that the MOE and MCCSS provide guiding principles for local decision-making and set standards for services provided by both DSBs and CTCs so that everyone, including parents, knows what to expect. Participants prioritized the need for more consistency across CTCs and DSBs in services available to children and families and also indicated that partners, including parents, children, and youth with disabilities, should be involved in the process of determining provincial standards and guiding principles for local decision-making. This finding aligns with Villeneuve and Shula (2012) where principles for school-based occupational therapy services were co-created by educator, parent and clinical partners to facilitate effective cross-sector collaboration. The principles agreed upon provided descriptive detail about roles and expectations of educators, parents and therapists:

Occupational therapy service supports educators with challenges related to educational programming and inclusion; parents understand the rationale 
for involving the occupational therapist; they understand the approach to service delivery and are invested in occupational therapy service; regular classroom teachers are actively involved with occupational therapy service, etc. (Villeneuve \& Shulha, 2012: p. 298).

Within this study, the experiences shared by participants were reflected upon by all partners which contributed to greater understanding and a collective will to change the current service delivery model and improve collaboration (Villeneuve \& Shulha, 2012).

\section{Limitations and Conclusion}

As a constructivist, interpretive study, the data generated through the online focus groups are time- and context-bound and took place during a global pandemic. In this regard, the study may be challenging to replicate. This study included a geographically diverse sample of participants; however, it is possible that participation appealed to those most passionate about the topic which may have narrowed the range of responses within the data collection. The findings of this study are specifically relevant to the Ontario, Canada education and SHSS political and cultural context which may limit transferability to other jurisdictions. The inquiry process utilized and the engagement of leaders in exploring their visions of effective collaboration in services for children and youth with or at risk of disability is applicable to other jurisdictions.

The findings of this exploratory study suggest that effective collaboration between DSB superintendents and directors of CTCs is hampered by a lack of clarity around the purpose and mandate of the school-based rehabilitation therapy program. There is a need for leaders to align a vision for services resolving the ambiguity between "school-based" services and services for "school-aged" children. The leaders also identified a need for clearly defined roles of all partners within the mandate, a focus on knowledge building to support all partners involved in services, and utilize existing evidence-based tools and resources appropriate in Ontario. Further research involving leaders from the health and education sectors are urgently needed to address effective collaboration in co-designing, implementing, and evaluating programs in schools for children with or at risk of disability.

\section{Conflicts of Interest}

The authors declare no conflicts of interest regarding the publication of this paper.

\section{References}

Anaby, D. R., Campbell, W. N., Missiuna, C, Shaw, S. R., Bennett, S., Khan, S., Tremblay, S., Kalubi-Lukusa, J. C., \& Camden, C. (2019). Recommended Practices to Organize and Deliver School-Based Services for Children with Disabilities: A Scoping Review. Child: Care, Health and Development, 45, 15-27. https://doi.org/10.1111/cch.12621

Barnes, K. J., \& Turner, K. D. (2001). Team Collaborative Practices between Teachers and 
Occupational Therapists. American Journal of Occupational Therapy, 55, 83-89. https://doi.org/10.5014/ajot.55.1.83

Braun, V., \& Clarke, V. (2012). Thematic Analysis. In H. Cooper, P. M. Camic, D. L. Long, A. T. Panter, D. Rindskopf, \& K. J. Sher (Eds.), APA Handbook of Research Methods in Psychology, Vol. 2: Research Designs: Quantitative, Qualitative, Neuropsychological, and Biological (pp. 57-71). American Psychological Association.

Campbell, W., Camden, C., \& Missiuna, C. (2016). Reflections on Using a Community-Based and Multisystem Approach to Transforming School-Based Intervention for Children with Developmental Motor Disorders. Current Developmental Disorders Report, 3, 129-137. https://doi.org/10.1007/s40474-016-0081-y

Cooperrider, D. L., \& Whitney, D. (2005). Appreciative Inquiry: A Positive Revolution in Change. Berrett-Koehler.

Coyne, I. T. (1997). Sampling in Qualitative Research. Purposeful and Theoretical Sampling; Merging or Clear Boundaries? Journal of Advanced Nursing, 26, 623-630. https://doi.org/10.1046/j.1365-2648.1997.t01-25-00999.x

Creswell, J. W., \& Creswell, J. D. (2017). Research Design: Qualitative, Quantitative, and Mixed Methods Approaches. Sage Publications.

DeLoach, K. P., Dvorsky, M., George, M. R. W., Miller, E., Weist, M. D., \& Kern, L. (2012). Interdisciplinary Collaboration in Launching a Large-Scale Research Study in Schools. Communique, 40, 6-11.

http://search.ebscohost.com.proxy.queensu.ca/login.aspx?direct=true\&db=eric\&AN=E J976835\&site=ehost-live

Deloitte \& Touche (2010). Review of School Health Support Services: Final Report. Ontario Ministry of Health and Long Term Care.

https://health.gov.on.ca/en/common/system/services/lhin/docs/deloitte_shss_review_r eport.pdf

Eron, L. (2021). Tutor Capacity Building Efficacy in Preservice Teacher Preparation for Inclusive Schools: An Exploratory Study. Open Journal of Social Sciences, 9, 398-413. https://doi.org/10.4236/jss.2021.97029

Fairbairn, M., \& Davidson, I. (1993). Teachers' Perceptions of the Role and Effectiveness of Occupational Therapists in Schools. Canadian Journal of Occupational Therapy, 60, 185-191. https://doi.org/10.1177/000841749306000404

Flynn, R., Albrecht, L., \& Scott, S. D. (2018). Two Approaches to Focus Group Data Collection for Qualitative Health Research. International Journal of Qualitative Methods, 17, 9 p. https://doi.org/10.1177/1609406917750781

Friend, M., \& Cook, L. (2003). Interactions: Collaboration Skills for School Professionals (4th ed.). Allyn \& Bacon.

Hernandez, S. J. (2013). Collaboration in Special Education: Its History, Evolution, and Critical Factors Necessary for Successful Implementation. US-China Education Review $B, 3,480-498$.

Hillier, S. L., Civetta, L., \& Pridham, L. (2010). A Systematic Review of Collaborative Models for Health and Education Professionals Working in School Settings and Implications for Training. Education for Health, 23, Article No. 393.

Karisa, A., McKenzie, J., \& De Villiers, T. (2020). To What Extent Is the Schooling System Willing to Change to Include Disabled Children? Disability \& Society, 35, 1520-1526. https://doi.org/10.1080/09687599.2020.1809351

Knibbs, K., Underwood, J., Macdonald, M., Schoenfeld, B., Lavoie-Tremblay, M. Crea-Arsenio, M. et al. (2010). Appreciative Inquiry: A Strength-Based Research Ap- 
proach to Building Canadian Public Health Nursing Capacity. Journal of Research in Nursing, 17, 484-494. https://doi.org/10.1177/1744987110387472

Kramer-Roy, D., Hashim, D., Tahir, N., Khan, A., Khalid, A., Faiz, N. et al. (2020). The Developing Role of Occupational Therapists in School-Based Practice: Experiences from Collaborative Action Research in Pakistan. British Journal of Occupational Therapy, 83, 375-386. https://doi.org/10.1177/0308022619891841

Learning Disability Association Ontario (LDAO) (2020). https://www.ldao.ca/ldao-services/public-policy-advocacy/responses-and-letters/

Lincoln, Y. S., \& Guba, E. G. (1985). Naturalistic Inquiry(1st ed.). Sage Publications.

Manning, K. (1997). Authenticity in Constructivist Inquiry: Methodological Considerations without Prescription. Qualitative Inquiry, 3, 93-115. https://doi.org/10.1177/107780049700300105

Missiuna, C. A., Pollock, N. A., Levac, D. E., Campbell, W. N., Whalen, S. D., Bennett, S. M. et al. (2012). Partnering for Change: An Innovative Schoolbased Occupational Therapy Service Delivery Model for Children with Developmental Coordination Disorder. Canadian Journal of Occupational Therapy, 79, 41-50.

https://doi.org/10.2182/cjot.2012.79.1.6

Missiuna, C., \& Hecimovich, C. (2015). Partnering for Change Implementation and Evaluation, 2013-2015. CanChild. https://www.partneringforchange.ca/

Nochajski, S. M. (2001). Collaboration between Team Members in Inclusive Educational Settings. Occupational Therapy in Health Care, 15, 101-112. https://doi.org/10.1080/J003v15n03_06

Ontario Ministry of Children, Community and Social Services (OMCCSS) (2018). Ontario's Special Needs Strategy.

http://www.children.gov.on.ca/htdocs/English/professionals/specialneeds/strategy.aspx

Ontario Ministry of Education (OME) (1984). Policy/Program Memorandum No. 81. http://edu.gov.on.ca/extra/eng/ppm/81.html

Ontario Society of Occupational Therapists (OSOT) (n.d.). Changes to School-Based Rehabilitation Services (SBRS).

https://www.osot.on.ca/TAGGED/News/January_2019_Changes_to_School_Based_Re habilitation_Services.aspx?WebsiteKey=5d041b61-13bc-4299-a851-c8d8d533ed8a

Phoenix, M., Dix, L., DeCola, C., Eisen, I., \& Campbell, W. (2021). Health Professional-Educator Collaboration in the Delivery of School-Based Tiered Support Services: A Qualitative Case Study. Child: Care, Health and Development, 47, 367-376. https://doi.org/10.1111/cch.12849

Rosenbaum, P., \& Gorter, J. W. (2011). The "F-Words" in Childhood Disability: I Swear This Is How We Should Think! Child: Care, Health and Development, 38, 457-463. https://doi.org/10.1111/j.1365-2214.2011.01338.x

Rossetti, Z., Burke, M. M., Hughes, O., Schraml-Block, K., Rivera, J. I., Rios, K. et al. (2021). Parent Perceptions of the Advocacy Expectation in Special Education. Exceptional Children, 87, 438-457. https://doi.org/10.1177/0014402921994095

Shasby, S. \& Schneck, C. (2011). Commentary on Collaboration in School-Based Practice: Positives and Pitfalls. Journal of Occupational Therapy, Schools, \& Early Intervention, 4, 22-33. https://doi.org/10.1080/19411243.2011.573243

Slaughter, G. (2018). Doug Ford's Progressive Conservatives Win Majority in Ontario. CTV News.

https://ctvnews.ca/mobile/canada/doug-ford-s-progressive-conservatives-winmajorityin-ontario-1.3963986 
VanderKaay, S., Dix, L., Rivard, L., Missiuna, C., Ng, S., Pollock, N. et al. (2021). Tiered Approaches to Rehabilitation Services in Education Settings: Towards Developing an Explanatory Programme Theory. International Journal of Disability, Development and Education, 1-22. https://doi.org/10.1080/1034912X.2021.1895975

Villeneuve, M. (2009). A Critical Examination of School-Based Occupational Therapy Collaborative Consultation. Canadian Journal of Occupational Therapy, 76, 206-218. https://doi.org/10.1177/000841740907600s05

Villeneuve, M. A., \& Shulha, L. M. (2012). Learning Together for Effective Collaboration in School-Based Occupational Therapy Practice. Canadian Journal of Occupational Therapy, 79, 293-302. https://doi.org/10.2182/CJOT.2012.79.5.5

Webster, C. A., Glascoe, G., Moore, C., Dauenhauer, B., Egan, C. A., Russ, L. B. et al. (2020). Recommendations for Administrators' Involvement in School-Based Health Promotion: A Scoping Review. International Journal of Environmental Research and Public Health, 17, Article No. 6249. https://doi.org/10.3390/ijerph17176249

Willig, C., \& Rogers, S. (2017). The Sage Handbook of Qualitative Research in Psychology. Sage Publications. https://doi.org/10.4135/9781526405555

Wintle, J., Krupa, T., Cramm, H., \& DeLuca, C. (2017). A Scoping Review of the Tensions in OT-Teacher Collaborations. Journal of Occupational Therapy, Schools, \& Early Intervention, 10, 327-345. https://doi.org/10.1080/19411243.2017.1359134 